Revue

Revue de l'histoire des religions

de Ihistoire des religions

\title{
Pierre GISEL et Jean-Marc TÉTAZ (dir.), Revisiter la
}

\section{Réforme. Questions intempestives}

Lyon, Éditions Olivétan, 2017

Olivier Marin

\section{(2) OpenEdition}

\section{Journals}

Édition électronique

URL : https://journals.openedition.org/rhr/10678

DOI : 10.4000/rhr.10678

ISSN : 2105-2573

Éditeur

Armand Colin

Édition imprimée

Date de publication : 1 septembre 2020

Pagination : 465-467

ISBN : 978-2-200-93327-2

ISSN : 0035-1423

Référence électronique

Olivier Marin, « Pierre Gısel et Jean-Marc Tétaz (dir.), Revisiter la Réforme. Questions intempestives »,

Revue de l'histoire des religions [En ligne], 3 | 2020, mis en ligne le 01 janvier 2021, consulté le 06 janvier 2023. URL : http://journals.openedition.org/rhr/10678; DOl : https://doi.org/10.4000/rhr.10678

Ce document a été généré automatiquement le 6 janvier 2023

Tous droits réservés 


\title{
Pierre GISEL et Jean-Marc TÉTAZ (dir.), Revisiter la Réforme. Questions intempestives
}

Lyon, Éditions Olivétan, 2017

\author{
Olivier Marin
}

\section{RÉFÉRENCE}

Pierre GISEL et Jean-Marc TÉTAZ (dir.), Revisiter la Réforme. Questions intempestives, Lyon, Éditions Olivétan, 2017, 199 p., 22,5 cm, 18 €, ISBN 978-2-35479-421-7.

1 En Suisse comme ailleurs, le cinq-centième anniversaire de la Réformation a suscité une floraison d'ouvrages commémoratifs d'inégale valeur. L'Espace culturel des Terreaux, sous la houlette de son président, Pierre Gisel, et d'un collègue lausannois de ce dernier, Jean-Marc Tétaz, a eu l'heureuse idée de consacrer un cycle de conférences à l'héritage intellectuel du protestantisme et à la relecture qu'il appelle. Le présent ouvrage qui en est issu se distingue par son ouverture disciplinaire : les contributeurs se ventilent entre la théologie (Marc Faessler, Marc Vial et les deux architectes du volume), l'histoire moderne et contemporaine (Claire Soussen et Valentine Zuber) et la philosophie politique (Jean-Claude Monod). Reconnaissons aussi d'emblée aux organisateurs le bon sens d'avoir renoncé à poursuivre la chimère de l'exhaustivité. Seuls trois points névralgiques ont été retenus, en raison des effets rémanents qui leur sont attribués, à tort ou à raison, sur la construction de la modernité. Ce pari nous vaut un échantillon de huit denses articles, qui oscillent entre présentation de l'état de l'art et essais incisifs.

2 Le premier thème concerne les rapports des Réformateurs au judaïsme. Claire Soussen retrace l'évolution en la matière de Martin Luther, dont on sait qu'il espérait initialement que les juifs se rallieraient à la Réformation. Après avoir dû faire le deuil de ce mirage, le théologien de Wittenberg passa à un rejet sans nuance, comme en 
témoignent ses violents traités anti-juifs des années 1540. Peut-être l'historienne exagère-t-elle cependant la rupture, si l'on en juge par le livre récent de Thomas Kaufmann, qui plaide pour la continuité (Les juifs de Luther, Genève, 2017). Jean-Marc Tétaz montre, pour sa part, comment l'antijudaïsme médiéval s'est maintenu chez Luther, tout en se déplaçant: au lieu de l'accusation de meurtres rituels, c'est désormais l'argument de la Scriptura sola et de l'univocité de la Bible qui a été brandi contre les juifs. En dernier lieu, Marc Faessler se penche sur le cas de Calvin, chez lequel il diagnostique, en se fondant sur vingt-trois réponses que le Genevois laissa à sa mort sur sa table de travail, une plus grande ouverture à la promesse dont les juifs sont les dépositaires. Encore s'agit-il d'un exercice d'école, la cité n'abritant plus de juifs en chair et en os depuis que l'évêque catholique les en avait expulsés, en 1490. C'est donc la difficile question de la relation entre discours et pratique et du passage à l'acte que cette première section pose en filigrane.

Le deuxième axe tourne, de manière assez attendue, autour de la liberté individuelle et de la filiation supposée entre Réformation et démocratie. J.-Cl. Monod et V. Zuber en traitent à deux voix : le premier se focalise sur la fortune de cette question disputée dans la philosophie et la sociologie allemande, depuis Hegel jusqu'à Troeltsch en passant par Weber, tandis que la seconde examine la discussion française sur les origines protestantes des droits de l'homme. Quoi qu'il en soit des différences entre les contextes nationaux d'une part, et entre les traditions luthérienne et calviniste d'autre part, il en ressort une convergence quant à la relativisation des effets politiques du protestantisme. De part et d'autre du Rhin, on s'accorde en effet à considérer aujourd'hui que liberté religieuse et liberté civile n'allaient pas de pair pour les Réformateurs, même si leur révolte contre Rome a pu entraîner sur le long terme des conséquences imprévues. L'expérience de la Seconde Guerre mondiale a directement contribué à ce désenchantement critique, ce qui ne va d'ailleurs pas sans susciter des difficultés : comme le fait remarquer incidemment J.-Cl. Monod (p. 91), la dénonciation actuelle de la servilité politique imputée au luthéranisme n'est-elle pas aussi anachronique que la stylisation antérieure de Luther en père de toutes les libertés ?

4 La dernière partie du livre est probablement la plus originale et la plus neuve. Elle entend remettre au premier plan un motif cher à Luther, celui du Deus absconditus (cf. Isaïe 45, 5). Ainsi que le rappelle Marc Vial, cette idée selon laquelle Dieu demeure différent de celui qui s'est révélé dans la figure du Christ semble avoir été périmée par la réfutation en règle due à Karl Barth. L'auteur montre néanmoins, en se référant au dogmaticien de Tübingen Eberhard Jüngel auquel il vient de consacrer une synthèse remarquée (Pour une théologie de la toute-puissance de Dieu, Paris, 2016), que la réalité du mal dans le monde atteste qu'il subsiste bien, sinon un être caché de Dieu, du moins une providence cachée. Voilà une introduction aussi limpide que brillante au débat entre ces trois géants de la théologie protestante. Dans un style hélas plus alambiqué, l'essai suivant de Jean-Marc Tétaz tente lui aussi de réhabiliter le thème du Dieu caché pour mieux faire droit à la diversité des religions. On voit là comment, par deux voies distinctes, un théologoumène mis entre parenthèses durant deux siècles se met à rejouer dans l'actualité.

On aurait mauvaise grâce à relever les lacunes de l'ouvrage. La plus gênante est sans doute l'exclusion délibérée de la Réformation radicale, qui aurait pourtant pu apporter des éclairages assez différents. Mais prenons ce petit livre pétillant pour ce qu'il est : 
moins une synthèse qu'un exercice décapant de lucidité, qui sait confronter l'histoire de la Réformation et les enjeux présents sans jamais céder à un concordisme facile.

AUTEURS

OLIVIER MARIN

Université Paris Nord - Sorbonne Cité, Paris. 